Int. J. Electrochem. Sci., 13 (2018) 10948 - 10960

\title{
Electrodeposition of Nanocrystalline Aluminium from 1-Ethyl- 3-methylimidazolium Chloroaluminate with Niacinamide as an Efficient Additive
}

\author{
Yong Zheng ${ }^{1, *}$, Yongjun Zheng ${ }^{1}$, Qian Wang ${ }^{2}$, Zhen Wang ${ }^{1}$, Conghu Peng ${ }^{1}$ \\ ${ }^{1}$ Department of Chemistry and Environmental Engineering, Anyang Institute of Technology, Anyang \\ 455000, Henan, P. R. China \\ ${ }^{2}$ State Key Laboratory of Multiphase Complex Systems, Institutes of Process Engineering, Chinese \\ Academy of Sciences, Beijing 100190, P. R. China \\ *E-mail: yzheng83@126.com
}

doi: $10.20964 / 2018.11 .93$

Received: 9 July 2018 / Accepted: 13 September 2018 / Published: 1 October 2018

\begin{abstract}
Nanocrystalline aluminium has been used as a promising energetic material due to its unique properties. However, the traditional methods for nanocrystalline aluminium production suffer from many inherent problems, which restrict the large-scale industrial application. In this paper, a systematic study was carried out on the nucleation mechanism and electrodeposition behaviour of nanocrystalline aluminium in Lewis acidic 1-ethyl-3-methylimidazolium chloroaluminate ionic liquid. It was found that niacinamide could be used as an effective additive in the preparation of nanocrystalline aluminium. According to electrochemical measurements and computational calculations, niacinamide was highly electroactive and polarized, which is probably attributed to nonuniform distributions of positive and negative charges on niacinamide. Its strong interaction with the electrode and subsequent adsorption onto the surface of aluminium nuclei prevented the further growth of crystals. Consequently, nanocrystalline aluminium was obtained at $313.2-333.2 \mathrm{~K}$ and $3-6 \mathrm{~mA} / \mathrm{cm}^{2}$ from 1-ethyl-3-methylimidazolium chloroaluminate that contained $8-12 \mathrm{mmol} / \mathrm{kg}$ niacinamide. Smooth and compact aluminium crystals with a minimum grain size of $20-30 \mathrm{~nm}$ could be electrodeposited at $313.2 \mathrm{~K}$ and $6 \mathrm{~mA} / \mathrm{cm}^{2}$ with $8-12 \mathrm{mmol} / \mathrm{kg}$ niacinamide. The molar concentration of additive, temperature and current density were confirmed as the major influencing factors in the electrodeposition of nanocrystalline aluminium from the chloroaluminate ionic liquid. It is expected that this work may be useful for the future preparation and application of nanocrystalline aluminium.
\end{abstract}

Keywords: nanocrystalline aluminium; ionic liquid; electrodeposition; niacinamide

$\underline{\text { FULL TEXT }}$ 
(C) 2018 The Authors. Published by ESG (www.electrochemsci.org). This article is an open access article distributed under the terms and conditions of the Creative Commons Attribution license (http://creativecommons.org/licenses/by/4.0/). 